\title{
NIETZSCHE CONTRA WAGNER: UNA DIATRIBA ANTE EL ROMANTICISMO MUSICAL
}

\author{
Carolina Rodríguez $R$. \\ Universidad Santo Tomás
}

Recibido: febrero 16 de 2005

Aprobado: abril 1 de 2005

\section{Resumen}

El texto pretende indagar en torno a una nueva perspectiva para comprender los encuentros y desencuentros acaecidos entre Nietzsche y Wagner. El propósito es encuadrar la discusión en el escenario del Romanticismo, tal como lo sugieren filósofos de la música del talante de Fubini y Neubauer. El resultado de este abordaje es sustancialmente el siguiente: hay una convergencia entre la estética wagneriana y la filosofía del joven Nietzsche, dado que a través del Romanticismo musical las dos propuestas confluyen en la necesidad de recuperar el drama musical griego como paradigma de una forma de arte total. Por otra parte, la separación conceptual entre Wagner y Nietzsche debe entenderse desde la adhesión que este último hizo al proyecto de una música absoluta, separada del teatro.

\section{Palabras Clave}

Romanticismo, drama musical, ópera, teatro, música absoluta, música programática

\section{Abstrac}

The text proposes to inquire around a new perspective to understand the agreements and disagreements that took place between Nietzsche and Wagner. The purpose is to present the discussion in the Romanticism scenary, as it is suggested by graced philosophers of music like Fubini and Neubauer. The outcome of this approach is: there is a convergence between the Wagnerian aesthetics and the philosophy of the young Nietzsche, granted that through the musical Romanticism the two proposals come together in the need to 
retrieve the Greek musical drama as paradigm of a total form of art. On the other hand, the conceptual distance between Wagner and Nietzsche must be understood from the assign that Nietzsche made to the project for an absolute music detached from theater.

\section{Key words}

Romanticism, musical drama, opera, theater, absolute music, planned music

Que el teatro no se convierta en dueño y señor de las artes Que el actor no se convierta en seductor del artista genuino Que la música no se convierta en el arte de mentir.

F. Nietzsche

\section{Introducción}

Las relaciones estéticas entre Nietzsche y Wagner han sido leídas desde diferentes perspectivas. Se destacan tópicos como las querellas personales, la opción de Nietzsche por la música de Brahms o la lectura mediada por metáforas fisiológicas que Nietzsche hizo de Wagner a partir de 1876, en donde estigmatizó su música como un signo cultural de debilidad, enfermedad y decadencia. También son relevantes como razones de la ruptura, la postura cristiana asumida por Wagner en Parsifal, su privilegio de la melodía, la modificación sustancial en la forma de trabajar elementos como la armonía y la tonalidad y, finalmente, el entusiasmo que Nietzsche expresó por la música mediterránea de Bizet, por el bel canto italiano y por el clasicismo.

Sin pretender desconocer el valor de estas tendencias interpretativas frente a la crisis entre el filósofo y el músico, en este escrito propongo una línea alternativa: leer los encuentros y desencuentros entre las estéticas nietzscheana y wagneriana a la luz de la co- nexión de ambas con el drama musical griego. Dicho en otros términos, es necesario explorar cómo la tragedia griega pretendió ser revivida por la ópera moderna, mediante un esfuerzo que fue considerado como desafortunado tanto por Nietzsche como por Wagner; de ahí que la necesidad de retornar al canon antiguo siguiendo una ruta diferente a la propuesta por la ópera es el punto de encuentro entre estas concepciones del arte. La divergencia está dada en que la solución intentada por Wagner, la del drama musical, fue rechazada virulentamente por Nietzsche, entre otras razones, por estar adscrita a los ideales del Romanticismo musical.

Así, esta nueva perspectiva permitirá entender que obras como Nietzsche contra Wagner, El caso Wagner y El crepúsculo de los ídolos, constituyen testimonios en donde el filósofo ya ha logrado superar el vínculo que tuvo en su juventud con dos influencias fundamentales: el Romanticismo musical y la filosofía de Schopenhauer, influencias que Wagner nunca pudo ni quiso abandonar, y que, al integrarlas a su nueva concepción del drama, el resultado obtenido fue tan deplo- 
rable, para el gusto de Nietzsche, como la ópera misma.

\section{El desprecio de lo musical}

Antes de empezar a desarrollar este recorrido, es necesario plantear que la música se convirtió en un problema filosófico para Nietzsche y Wagner, así como para los pensadores ilustrados, románticos e idealistas, en la medida en que históricamente se vivió el desprecio ante la música como una forma de arte menor, o, como quería Aristóteles, como un oficio práctico que no es digno de ser ejecutado por los hombres libres. Recuperar la dignidad de la música e ir más allá de la manualidad fue una empresa acometida por el espíritu romántico, en donde resultó representativa la labor de Schumann al reclamar para la música un nivel de equidad frente a las otras bellas artes. Parte de esta tarea fue adelantada también por el clacisimo a través de Mozart y Haydn, quienes pretendieron emancipar la labor del músico de la del siervo palaciego.

Como razones para la situación de desventaja de la música, Fubini ${ }^{1}$ atribuye la falta de conciencia de su propia historicidad, la ausencia de un estatuto teórico riguroso de la estética musical y, sobre todo, el carácter efímero de la música, completamente ligado al instante de la ejecución. La música, en mayor medida que la poesía, tiende a desvanecerse. También debe mencionarse el papel marginal consuetudinariamente desempeñado por la música, relegada siempre a ser un acompañamiento de la poesía o complemento de la función litúrgica.

De este papel secundario y accesorio de la música, se deriva un nuevo problema que también constituye materia de reflexión tan- to para Nietzsche como para Wagner: el de las relaciones entre poesía y música. Ellos son los herederos de un debate planteado entre Hegel -quien defiende la superioridad de la poesía- y Schopenhauer -quien sostiene el carácter privilegiado de la música. Esta confrontación fue posible, según señala Fubini, porque:

La música y poesía, además de ser ambas artes del tiempo y no del espacio, son también artes que se establecen sobre la posibilidad de articulación del sonido, sobre una elección de sonidos pertinentes con la consiguiente exclusión de otros no pertinentes, dentro de una cierta lengua, dentro de un cierto estilo, dentro de una cierta cultura².

La música, al igual que la poesía, es un arte del tiempo, porque es una forma de expresión que toma el tiempo como su verdadera materia. No obstante, la poesía se hizo más autónoma y ganó un espacio de mayor significatividad en las concepciones estéticas de Occidente, desde los griegos hasta la Ilustración. Solamente con el Romanticismo hemos de asistir a la reivindicación de la primacía de lo musical. Ahora bien, esta separación entre las artes dio lugar a una divergencia tal, que la reunificación no se consideró nunca como posible y propició el surgimiento de la ópera como un intento de articulación.

\section{Emergencia, fracaso y renovación de la ópera}

Así, la ópera nació en Italia en el año de 1598 con un grupo de intelectuales que, bajo la tutela de Giovanni de Bardi, se conoció como la Camerata Fiorentina. Se trató de una tertulia de humanistas que, recurriendo a lo

Enrico Fubini, Estética de la música (Madrid: Visor/ La balsa de Medusa, 2001).

Fubini, Estética ..., 29. 
mejor del espíritu renacentista, quiso revivir la esencia del drama musical griego. No obstante este ideal, el resultado obtenido por Giacomo Peri con Dafne, primer drama para música, y por las obras ulteriores del mismo género, fue todo un fracaso. Podría decirse que la ópera es el arte integral, porque vincula formas de expresión como la música vocal e instrumental, el teatro, la poesía, la danza, la pintura y la arquitectura. Sin embargo, la crítica no entendió que esta unión de elementos diversos diera lugar a una síntesis equilibrada, por calificarla como una yuxtaposición ecléctica de elementos inconexos.

Aunque la nueva forma de arte fue llevada a su madurez con Monteverdi, autores como Muratori y Hawkins sentenciaron que la ópera fue un género que nació muerto, estando condenado al colapso desde sus orígenes. Por otra parte, según Neubauer, surgieron en Italia varios debates en torno a la ópera, cuya multiplicidad es susceptible de ser reducida a dos cuestiones centrales, a saber: 1) si la ópera sigue los cánones tradicionales y 2) si podía ser moralmente edificante. Sólo en el cumplimiento de estos requisitos la ópera tendría razón de ser como forma de arte.

Al no encontrar una respuesta afirmativa ante las dos cuestiones anteriores, Muratori juzgó a la ópera como:

(...) una mostruosidad y un conglomerado de miles de improbabilidades... La ópera es una empresa extraña de poesía y música en la que el poeta y el compositor, molestados el uno por el otro en igual medida, logran tener suficientes problemas como para crear una obra desgraciada ${ }^{3}$.
De este modo, la ópera fue tenida como un género antinatural, inverosímil y absurdo, que cobra forma a través de un espectáculo ridículo, pesado y extravagante. Lo cierto es que "las óperas no sólo violaban las unidades de tiempo y espacio, sino también el principio aristotélico general según el cual los dramas deben imitar la acción humana”4. La ópera no satisfizo el ideal de representar las costumbres morales ni de desarrollar una forma musical de carácter mimético, en donde se diera un isomorfismo entre el sonido y la acción. La conclusión de Hawkins a este respecto es muy clara: la ópera no habla ni a la razón ni a las emociones, sino simplemente a la lujuria.

Como era de esperarse, aparecieron también defensores que intentaron considerarla como una expresión artística autónoma diferente a la tragedia. Esta fue la alternativa señalada por Smith, Schlegel y Schiller. Con ellos la ópera se convirtió en un entretenimiento espiritualmente elevado, que crea una serie de mundos posibles que no tienen por qué imitar al mundo real. A este respecto, Schiller dice que espera que surja:

(...) una forma más noble de tragedia a partir de la ópera, tal como ocurrió con los coros en las antiguas fiestas en honor de Baco. En la ópera se abandona la imitación servil de la naturaleza y, aunque fuera en nombre de la indulgencia, el Ideal podría introducirse de soslayo en el escenario. A través del poder de la música y de una estimulación armoniosa y más libre de los sentidos, la ópera pondría la mente en armonía con una sensibilidad estética más sutil. Incluso el pathos juega un papel más li-

\footnotetext{
John Neubauer, La emancipación de la música: El alejamiento de la mímesis en la estética del siglo XVIII (Barcelona: Visor, 1992) 205-206.

4 Neubauer, La emancipación ..., 207.
} 
bre aquí, puesto que está acompañado por la música, y lo milagroso, que, por fin, se tolera, nos haría ser, necesariamente, más indiferentes hacia el contenido ${ }^{5}$.

Aunque la ópera fue planteada como una forma legítima de entretenimiento y se llegó a negar su pretendido didactismo, echando por tierra el ideal platónico de una música educativa y "moralmente correcta”, y aunque se descartó también cualquier función mimética, estos intentos no fueron suficientes para salvar la cuestionada dignidad de la música a través de una forma de expresión señalada como sospechosa y hasta peligrosa. A esto hay que añadir el inconveniente antes indicado, el de las difíciles relaciones que se dieron en la ópera entre la música y la poesía, tal como señala Aron Copland:

Los compositores de óperas han hecho en la práctica una de estas dos cosas: o dieron a la letra un papel preponderante y usaron la música sólo como servidora del drama, o sacrificaron francamente la letra y la usaron tan sólo como percha para colgar su música. De suerte que todo el problema de la ópera se puede reducir a la estrepada de la letra por un lado y de la música por el opuesto $^{6}$.

En realidad, las reevaluaciones de la ópera transcurrieron de forma paralela a sus transformaciones, aunque su trayectoria, desde Peri y Caccini, hasta Gluck, constituye una espiral (y no una línea recta) que se inicia en la forma retórica inicial, pasa por los estilos veneciano y napolitano en los que domina la melodía, y vuelve, de la mano de Gluck, a un estilo en el que el texto es absolutamente preponderante.

Pues bien, la conciencia de los frustrados intentos de la ópera para erigirse como un género capaz de integrar todas las artes, de devolver la dignidad a la música y de evocar el drama musical griego, constituye la base de la estética wagneriana. Es en este momento en el que Richard Wagner se cree el depositario de una misión que fuera imposible de consumar para la tradición precedente y que está en sus manos cumplir. En una actitud abiertamente mesiánica, considera que a través de su obra no sólo se llegará a la emancipación de la música, sino del arte en cuanto tal. Asume de Rousseau la posibilidad de llegar a una unión originaria entre poesía y música; del Romanticismo retoma un elemento fundamental: la convergencia de todas las artes para alcanzar una expresividad más completa. Como testimonio de esto, dice:

Veía yo en la ópera una institución cuyo particular objetivo consiste en ofrecer una distracción y un entretenimiento a un público tan aburrido como ávido de placer; veía más su obligación de calcular un resultado pecuniario para hacer frente a los gastos exigidos por el pomposo aparato que tantos atractivos presenta, y no lograba ocultarme que sería una verdadera locura el intento de canalizar dicha institución hacia una meta diametralmente opuesta, es decir, aplicarla para que el pueblo se desprendiera de sus intereses vulgares y se elevara al culto y la inteligencia de las mayores grandezas y las mayores hon-

Neubauer, La emancipación ..., 212

6 Aron Copland, Cómo escuchar música (México: F.C.E., 1980) 167. 
duras que pueda concebir la mente humana ${ }^{7}$.

Por su parte, Nietzsche también estuvo de acuerdo en indicar cómo los esfuerzos eruditos realizados por la Camerata Fiorentina habían resultado decepcionantes porque fue un error retornar de una manera docta a lo antiguo, por lo cual era necesario esperar una reforma contundente para el destino de la música. Fue así como Wagner y Nietzsche confluyeron en el ideal de sacralizar el drama musical griego en cuanto forma suprema de arte. Frente a esto, el filósofo afirma que:

(...) sí, pues, mientras que aquí hemos de reconocer un desarrollo que avanza de manera natural, y que se continúa durante milenios, aquella genuina tragedia de la Antigüedad, la obra de arte de Esquilo y de Sófocles, ha sido inoculada al arte moderno de un modo arbitrario. Lo que hoy nosotros llamamos ópera, que es una caricatura del drama musical antiguo, ha surgido por una imitación simiesca directa de la Antigüedad: desprovista de la fuerza inconsciente de un instinto natural, formada de acuerdo con una teoría abstracta, se ha portado cual si fuera un homunculus producido artificialmente, como el malvado duende de nuestro moderno desarrollo musical ${ }^{8}$.

Nietzsche creyó asistir al espectacular renacimiento del ideal griego con Tristán e Isolda, hecho que le llevó a desafiar los férreos convencionalismos académicos de la comunidad filológica de su tiempo, para realizar en El origen de la tragedia en el espíritu de la música, una oda al wagnerianismo naciente. Dicho de otro modo, quiso hacer patente el estatuto teórico y estético subyacente en la mencionada obra musical, hecho que, por supuesto, fue de muy grato recibo para Wagner, pues para él:

(...) supondrá la materialización de toda su teoría estética, la posibilidad hecha realidad que su pensamiento quedase para la posteridad enunciado bajo el formato de la concepción filosófica, aspecto al que siempre había aspirado en sus escritos, caracterizados en muchas ocasiones por grandilocuencia de corte filosófico ${ }^{9}$.

Nietzsche encontró en Wagner un renacimiento del espíritu dionisiaco, una música capaz de expresar la profunda tensión existente entre el placer y el sufrimiento, entre la vida y la muerte. Según él, la música wagneriana ha sido capaz de captar la esencia de la tragedia griega y transportarla a un lugar y una época cuyo gusto artístico degenerado necesita ser redimido por la potencia embriagadora del arte verdadero. Fue así como el filósofo llegó a expresar lo siguiente:

(...) tomaba yo al conocimiento trágico como el más hermoso lujo de nuestra cultura, su derroche más espléndido, distinguido y arriesgado, que aún así le era lícito en razón de su sobreabundancia. De manera similar, me explicaba con razón la música de Wagner como expresión de una potencia dionisiaca del alma, en el que creía oír el terremoto con que una fuerza pri-

Eduardo Pérez Maseda, Música como idea, música como destino: Wagner-Nietzsche (Madrid: Tecnos, 1993) 98.

$8 \quad$ Friedrich Nietzsche, El drama musical griego (Madrid: Ediciones Siruela, 1999) 12.

9 Friedrich Nietzche, Nietzsche contra Wagner: El caso Wagner, eds. Giorgio Colli y Mazino Montinari, trad. José Luis Arántegui (Madrid: Ediciones Siruela, 2002) 12. 
mordial de la vida, estancada a lo largo de las edades, se abría por fin camino al aire libre sin importarle que todo lo que hoy se llama cultura pudiera desbaratarse a su paso ${ }^{10}$.

Colli y Montinari ${ }^{11}$ explican que para Nietzsche el arte wagneriano representó una restitución metafísica del valor de la música, que de alguna manera debía servir para la evolución espiritual de Alemania. Como todos sabemos, Nietzsche no tardará mucho en retractarse de la ampulosa generosidad de estos juicios, y sólo basta esperar a la aparición de las Consideraciones intempestivas para observar un rápido cambio en sus valoraciones estéticas.

\section{Wagner como músico romántico}

Se dice frecuentemente que el periodo romántico de Wagner es el referido a Tristán e Isolda, de manera que la lectura posterior de Feuerbach le llevaría a definirse como revolucionario, y la influencia de Schopenhauer lo orientaría hacia el pesimismo. Mi tesis contradice esta creencia y considera que en cada uno de sus periodos, aun en el pesimista, estuvo fuertemente marcado por el Romanticismo.

Uno de los elementos que evidencia la adscripción de Wagner a esta tendencia se expresa en la identificación realizada entre arte y verdad. De acuerdo a la opinión de Givone,

(...) es a partir del romanticismo cuando arte y verdad tratan de parecer solidarios, cómplices; hasta tal punto que el arte se impone en las poéticas o en las obras de arte como práctica de liberación de la verdad y la verdad se afirma en el ámbito científico o en el religioso por su naturaleza esencialmente mitopoiética o artística, sin más ${ }^{12}$.

El carácter romántico de la estética wagneriana la acerca a los argumentos defendidos por autores como Heidegger y Gadamer. Existe una relación entre arte y conocimiento, en la medida en que la naturaleza de la obra consiste en su capacidad para llegar a la esencia de las cosas. El arte permite captar la verdad de una manera directa, evitando los rodeos argumentativos propios de los discursos lógico-científicos. La naturaleza del arte no es sólo producir belleza, sino, ante todo, iluminar y desocultar la verdad. Para Wagner, "la misión del artista era la de redimir al hombre, para ello debía previamente desmitificar la realidad y mostrarle la verdad originaria” ${ }^{13}$.

Ahora bien, la manera en que el arte muestra la verdad no es conceptual sino simbólica. No es la operatividad racional del logos lo que debe esperarse de la obra estética, sino la construcción de una simbología compleja, capaz de afectar directamente la intuición, de una manera onírica e inconsciente, porque "la obra de arte hace conocer abiertamente lo otro, revela lo otro; es alegoría"14. Tanto para Wagner como para Heidegger el arte no es mimesis ni reproducción, sino captación de la esencia general de las cosas, porque la verdad es algo intemporal. De ahí precisamente que Nietzsche denuncie el barroquismo saturado de significación, porque

10 Nietzche, Nietzsche contra ..., 85.

11 G. Colli y M. Motinari, “Estudio preliminar”, Nietzsche contra Wagner: El caso Wagner, de Friedrich Nietzsche (Madrid: Ediciones Siruela, 2002) 10.

12 Sergio Givone, Desencanto del mundo y pensamiento trágico (Madrid: Visor/ La balsa de Medusa, Madrid, 1991) 85.

13 Nietzche, Nietzsche contra ..., 11.

14 Martin Heidegger, El origen de la obra de arte (Madrid: F.C.E., 1965) 41. 
"no es con la música con lo que Wagner ha conquistado a los jóvenes, es con la 'Idea': es la riqueza de enigmas de su arte, su juego del escondite tras de cien símbolos”15.

Por el contrario, en la estética nietzscheana se subvierte este ideal romántico, de modo que entre arte y verdad no existe ninguna relación. La verdad es una quimera perseguida torpemente por los filósofos; dada su naturaleza esquiva e inaprehensible, los ha tornado en seres taciturnos, que sólo se nutren de la savia de su erudición. El arte es expresión de la voluntad de poder, del instinto y de la vida, mientras que la búsqueda del saber representa un anhelo decadente y antinatural, una huida metafísica hacía el pretendido mundo verdadero.

La discusión sobre la relación entre el arte y la verdad es un requisito fundamental para entender la intencionalidad romántica propia de la estética wagneriana. En primer lugar, es necesario señalar las dificultades que el compositor manifiesta frente al racionalismo a ultranza, y en general, ante los productos de la modernidad, en términos de la sacralización de la razón, la ciencia y el progreso. Da a entender que la crisis del arte tiene una importante conexión con el predominio de la actitud cientificista, que desconoce el papel de la intuición y la creatividad. Si bien este es un punto de conexión con Nietzsche, la diferencia está dada en que el filósofo no resuelve concientemente el problema de la cultura moderna con una solución romántica.

Por el contrario, más allá de la vanguardia y la moda imperante, Wagner cree fundar las bases para un tipo de obra que está orientada a captar y expresar lo esencial. Tarea es del arte, y particularmente de la música, servir de modelo a diferentes formas de conocimiento y experiencia, para lograr asir el alma del mundo. Las demandas que Wagner le plantea a su proyecto artístico están en relación con la estética romántica alemana. Existen ecos de Wackenroder (la música como acceso a esencias místicas e inefables), de Schelling (el mito como núcleo del pensamiento trágico), de Schopenhauer (la música como alma del mundo). Esta profunda inserción con la tradición permite que el proyecto wagneriano tenga relaciones muy profundas con la estética posterior, en particular, con la heideggeriana (el arte como desocultación de la verdad). Fubini indica que en el Romanticismo "la música puede asumir una misión reveladora de verdades de otro modo inaccesibles al hombre ${ }^{16 ",}$, misión que se desarrolla de una forma especial en Wagner,

Lo anterior prueba que, si bien no puede decirse que Wagner haya sido un lector de Schelling o de Wackenroder -como si lo fue de Schopenahuer-, su manifiesto programático estuvo fuertemente en contacto con la tradición filosófica y artística emparentada con el Romanticismo. GregorDellin $^{17}$, explica que la intensa actividad social e intelectual del compositor le permitió compartir tertulias con lo más granado de la burguesía culta de su época, gracias a lo cual fue incorporando ideas y categorías que no abordó directamente, pero que llegó a integrar con éxito a su concepción del drama musical.

Además de la identificación entre arte y verdad, un segundo elemento que Wagner retoma del Romanticismo lo constituye su opción por una música programática. Esta

\footnotetext{
Nietzche, Nietzsche contra ..., 42.

Fubini, Estética ..., 121.

17 Martin Gregor-Dellin, Richard Wagner, 1, 1821, 1964 (Madrid: Alianza Música, 1983).
} 
opción está relacionada con una dualidad en relación con el lenguaje. Una primera tendencia, representada fundamentalmente por Wackenroder, considera que el lenguaje es una facultad limitada, que aparece desbordada por la capacidad intuitiva de la música; de este modo, "la pobreza expresiva del lenguaje ofrece una nueva prominencia a la música instrumental”18. De otro lado, la orientación opuesta también hace parte del Romanticismo y pretende encontrar una mayor significatividad del lenguaje a través de la música, lo cual equivale a erigir a la música en un lenguaje privilegiado; esta es la ruta seguida por Schopenhauer y posteriormente por Wagner.

De lo anterior se deriva la aspiración a un lenguaje autónomo de los sentimientos, particularmente expresivo, ideal que es muy caro a Wagner. La música cumple una intencionalidad comunicativa mediante un modelo denotativo similar al del lenguaje verbal, que narra eventos del mundo externo y las emociones propias de la subjetividad humana; dice algo y tiene un contenido semántico. De ahí que Nietzsche reproche a Wagner que “él acrecentó hasta lo inconmensurable las capacidades de la música como lenguaje"19.

Dos elementos son señalados como aberraciones de la música wagneriana por parte de Nietzsche: la tendencia hacia el infinito y pretensión de significado, porque absoluto y semanticidad se convierten en objetos de sospecha. Nietzsche cree constatar el carácter no referencial de la música, y con ello se identifica con la tendencia irracionalista del Romanticismo, la cual defiende la asemanticidad del sonido, al subrayar la transparencia de la palabra en oposición a la densa indeterminación de la música (nuevamente Wackenroder). En virtud de ello, no perdona que Wagner se sitúe en el otro extremo del Romanticismo al buscar lo inefable a través del arte y al experimentar una mayor capacidad expresiva a través de la música. Nietzsche se separa de Rousseau y Diderot, al negar que la tarea musical sea la de revelar la emoción. La música no es expresiva. Por el contrario, nuestro compositor se acerca al Romanticismo porque quiere separarse del manierismo musical y de los cánones estereotipados, marcados por el efectismo y la artificialidad, para poner de manifiesto el flujo de la subjetividad.

Ahora bien, retomando argumentos de Neubauer $^{20}$ y Dahlahus ${ }^{21}$, es posible aclarar que, a diferencia de lo que Nietzsche cree, el Romanticismo no se disuelve en misticismo, intimismo, emoción e intuición. De hecho, los autores mencionados ilustran con éxito que afirmar que la estética romántica está centrada en las pasiones, mientras que la estética racionalista está orientada por la estructura, no es más que un prejuicio frecuente, del que evidentemente Nietzsche no logró sustraerse, lo cual le llevó a declarar de Wagner que: “(...) ése es nuestro más grande melancólico de la música, lleno de miradas, de delicadezas y palabras de consuelo en las que nadie se había anticipado, maestro en los tonos de una felicidad lánguida y pesarosa”22.

En realidad, dentro del Romanticismo sólo algunos autores, como Schlegel, Schelling y Jean Paul, defendieron el carácter eminente-

\footnotetext{
Neubauer, La emancipación ..., 295.

Nietzche, Nietzsche contra ..., 37.

Neubauer, La emancipación ...

Carl Dahlhaus, La idea de música absoluta (Barcelona: Idea Books, 1999).

Nietzche, Nietzsche contra ..., 36.
} 
mente emocional de la música. Otros, como Novalis, se encargaron de explorar una dimensión más intelectual y matemática. Lo cierto es que Neubauer caracteriza la música romántica desde una perspectiva dual, en donde interactúan en tensión permanente lo pitagórico y lo místico, lo formal y lo emocional, dualidad plenamente heredada por Wagner.

El calificativo de absoluto en la música romántica puede entenderse a la luz de dos puntos de vista. En primer lugar, desde una acepción mística y metafísica. En segunda instancia, a partir del predominio del arte por el arte, como una función sin remisión a contenidos externos, puramente autorreferencial y formal. Como quiera que sea, el elevado grado de abstracción es el punto conector entre misticismo y formalismo. Nótese en este punto que Nietzsche dice estar en contra del Romanticismo y, en nombre de eso, niega la vertiente mística que alguna vez suscribió en su juventud. Sin embargo, está anclado en una función autorreferencial del arte, que le lleva paradójicamente a negar el Romanticismo desde el Romanticismo mismo.

De acuerdo con lo anterior, el Romanticismo ofrece dos salidas con respecto a la música: la absoluta, asumida por Nietzsche, y la programática, escogida por Wagner para transmitir su particular visión del hombre, de la naturaleza y la sociedad; temía no pasar por ligero y por ello "Wagner pasó toda su vida repitiendo una frase: ¡que su música no significaba sólo música! ¡Sino más! ¡Infinitamente más!”23. Como quiera que sea, el estatuto conceptual de la música programática le permitió a Wagner formular su idea de drama musical, porque:

La exaltación de la música programática se encuadra perfectamente en la aspiración romántica de la convergencia de las artes bajo el dominio de la música (ya Novalis afirmó que la música representa el punto límite al que tienden todas las artes, y en particular la poesía) ${ }^{24}$.

Por el contrario, Nietzsche se mueve en el ámbito que Fubini ha denominado como hedonista. La música es una forma de arte cuyo fin está orientado a producir placer sensible y no conocimiento. Nietzsche se acerca a los teóricos del formalismo puro, al rechazar la tentativa wagneriana de realizar una fusión entre música y literatura, porque la música carece de cualquier poder expresivo o significativo, debido a su carácter puramente instrumental. Como es evidente, la cuestión de la semanticidad de la música es uno de los problemas más importantes de la estética musical, y a su vez subsume el complicado asunto de la jerarquía y relaciones entre música y poesía.

Wagner es el heredero directo de Gluck, en la medida en que este compositor se interesó por alcanzar la unidad dramática de la ópera; la música no es un añadido accidental de la obra teatral ni la acción un pretexto para el desarrollo independiente de acordes y arias. Como es evidente, del programa de Gluck retoma la tarea representativa y programática de la música. Copland coincide con Nietzsche al afirmar que Gluck intentó hacer más racional la ópera, ya que puso la idea dramática por encima del lucimiento

$23 \quad$ Nietzche, Nietzsche contra ..., 42.

${ }^{24}$ Fubini, Estética ..., 125. 
de los cantantes y produjo un tipo de música subordinado a los intereses del texto literario.

En lo que a Wagner respecta, el drama musical tenía que ser diferente de la ópera porque no es una colección de números aislados, como coros, recitativos, arias, etc.; es un fluir narrativo y escénico continuo, todo en aras de un mayor realismo dramático. Por otra parte, está la introducción del levmotiv, como asociación de un cliché musical a una determinada situación o personaje, lo que contribuyó a subrayar la conexión entre la idea y el sonido.

Pero Copland es enfático en señalar que en realidad Wagner no fue capaz de ir más lejos que Gluck, y que en realidad nunca pudo superar o mejorar la ópera a través del drama musical; tampoco logró la unidad sintética de todas las artes. Copland, a diferencia de Nietzsche, considera que Wagner es más músico que autor dramático. Ahora bien, pese a los juicios de Copland, me parece necesario admitir que, si bien con Wagner no se llegó a la obra de arte total, de todos modos sí se alcanzó una mayor interdependencia entre música, poesía y acción teatral, hecho sin precedentes para la historia de la ópera. Aunque el drama musical no consumó el ideal socialista de redimir a la humanidad y señalar el camino hacia la sociedad del futuro, lo importante es que sí evidenció una perfección formal desconocida en los dramas precedentes.

Lo cierto es que para Nietzsche el drama musical wagneriano no resultó ser un producto artístico de mayor calidad, en comparación con la ópera convencional. El resultado fue un esfuerzo intelectualista y erudito, un híbrido extraño que reivindica el racionalismo, pero que al mismo tiempo promueve la expresión de los sentiemientos. Así, Wagner es a la ópera lo que Sócrates a la filosofía.

La crítica nietzscheana se centra en la traición a la música en aras del predominio de una forma de arte que juzga como menor: el teatro. Así, Wagner se convierte en un artista sacrílego porque pretende emancipar la música de la poesía para subordinarla a las artes escénicas; "llegó a no componer ya música para el oído, sino para el ojo”.

Surgiría para la música un peligro como no cabría pensarlo mayor: una degeneración del sentido rítmico, el caos en lugar del ritmo. El peligro llega a su punto culminante cuando esa música se apoya cada vez más en una mímica y un arte escénico que ninguna ley plástica gobierna, que busca el efecto y nada más... Lo espressivo a cualquier precio, la música reducida a servidumbre, a la esclavitud de la pose: eso sí que es el final $^{25}$.

El gran inconveniente que Nietzsche tiene con el teatro wagneriano es que, a diferencia de la tragedia griega, no busca transfigurar la realidad, sino falsearla, no asumir el dolor y el desgarramiento, sino evadirlo. El teatro no es más que una impostura burguesa que cumple un papel similar al de la metafísica: crear realidades alternas. Por ello, "hoy el músico se está volviendo actor, y cada vez más su arte se desarrolla como talento para mentir" ${ }^{26}$.

Nietzsche parece coincidir con Herder cuando afirma que "el gran defecto de la música moderna es representar el mundo externo, pues si la música abandona su dominio y

\footnotetext{
Nietzche, Nietzsche contra ..., 83.
}

26 Nietzche, Nietzsche contra ..., 34. 
emula al ojo capaz de pintar, deja de ser música y se convierte en cacofonía de sonidos" ${ }^{27}$. Es implacable en su juicio: dice que Wagner quiere pasar por dramaturgo, pero no es tal. Lo único que le interesa es el efecto. En realidad, es músico, retórico, actor y seudodramaturgo. Crea un tipo de arte de carácter sensiblero para que le guste a las mujeres, y corriente, para que sea de preferencia de las masas. "El teatro es una demolatría en asuntos de gusto, una rebelión de las masas, un plebiscito contra el buen gusto" ${ }^{28}$. Ahora bien, el Romanticismo es el arte para la plebe educada, que aspira a lo sublime, levantarse, ascender. La sed de infinito en el Romanticismo no es más que el último estertor del idealismo hegeliano: búsqueda de esencias, profesión de nacionalismo, opción por la verdad, reivindicación del espíritu, sacralización de la Idea como totalidad. Así, el arte wagneriano es sólo una de las formas de expresión de hegelianismo mezclado con el pesimismo de Schopenhauer, y por eso hay que combatirlo.

Se da en esta estética idealista una inexplicable alianza entre belleza y enfermedad que sólo intenta conmover los afectos. Produce una "melodía infinita" que está hecha para nadar y no para bailar. Wagner, dominado por la literatura, es calificado por Nietzsche como un romántico decadente, fanático de la expresión. Su estética debe ser refutada porque la necesidad de redención es lo más contrario al espíritu griego, promueve el “evangelio de los más bajos”.

¡Ah, esos griegos! ¡Esos sí que sabían vivir! ¡Para eso hace falta quedarse plantado con gallardía en la superficie, en los pliegues, en la piel, adorar la apa- riencia, creer en formas, sonidos y palabras, en el Olimpo eterno de la apariencia! ${ }^{29}$.

\section{A manera de conclusión}

Como conclusión de la polémica entre la estética nietzcheana y la wagneriana, podemos retomar las siguientes palabras de Fubini, que sintetizan el punto central de la cuestión:

El desacuerdo que se creó entre Wagner y Nietzsche puede explicarse con las dos posibles salidas de la concepción romántica de la música, aun contando con su común raíz schopenhaueriana: Wagner lleva hasta sus últimas consecuencias el concepto roussoniano y herderiano de la unión entre poesía y música, mientras que Nietzsche desarrolla el principio, ya presente en Wackenroder, en Hoffmann, en Schopenhauer y en tantos otros pensadores románticos, de absoluto privilegio y autonomía de la música instrumental $^{30}$.

Nietzsche sigue atrapado en los límites del Romanticismo, al adherirse al predominio de una música absoluta. Las ambigüedades del Romanticismo musical no le permitieron reconocer que tanto él como Wagner seguían siendo herederos de esta tradición, aunque siguieran rutas distintas; al optar por lo instrumental, capituló de la fe profesada en su juventud: la posibilidad de revivir el drama musical griego. Con Thomas Harrison tenemos que decir que para Nietzsche "el arte no brinda respuestas, sino sólo una pregunta, y todo a su alrededor, la vida" ${ }^{31}$.

\footnotetext{
Neubauer, La emancipación ..., 239.

Nietzche, Nietzsche contra ..., 49.

Nietzche, Nietzsche contra ..., 97.

Fubini, Estética ..., 127.

1 Thomas Harrison, "Filosofía del arte, filosofía de la muerte”, Filosofía y poesía: Dos aproximaciones a la verdad, de Gianni Vattimo (Barcelona: Gedisa, 1999) 14.
} 


\section{Bibliografía}

Colli, G. y Motinari, M. "Estudio preliminar”. Nietzsche contra Wagner: El caso Wagner, de Friedrich Nietzsche. Madrid: Ediciones Siruela, 2002.

Copland, Aron. Cómo escuchar música. México: F.C.E., 1980.

Dahlhaus, Carl. La idea de música absoluta. Barcelona: Idea Books, 1999.

Fubini, Enrico. Estética de la música. Madrid: Visor/ La balsa de Medusa, 2001.

Gadamer, Hans Georg. Mito y razón. Barcelona: Paidós, 1992.

Givone, Sergio. Desencanto del mundo y pensamiento trágico. Madrid: Visor/ La balsa de Medusa, 1991.

Gregor-Dellin, Martin. Richard Wagner. 1, 1821, 1964. Madrid: Alianza Música, 1983.

Harrison, Thomas. "Filosofía del arte, filosofía de la muerte". Filosofía y poesía: Dos aproximaciones a la verdad, de
Gianni Vattimo. Barcelona: Gedisa, 1999.

Heidegger, Martin. El origen de la obra de arte. México: F.C.E., 1965.

Neubauer, John. La emancipación de la música: El alejamiento de la mímesis en la estética del siglo XVIII. Barcelona: Visor, 1992.

Nietzsche, Friedrich. El drama musical griego. Madrid: Ediciones Siruela, 1999.

- Nietzsche contra Wagner: El caso Wagner. Eds., Giorgio Colli y Mazino Montinari. Trad., José Luis Arántegui. Madrid: Ediciones Siruela, 2002.

-. El origen de la tragedia en el espíritu de la música. Prólogo, traducción y notas, Andrés Sánchez Pascual. Madrid: Alianza Editorial, 1984.

Pérez Maseda, Eduardo. Música como idea, música como destino: WagnerNietzsche. Madrid: Tecnos, 1993.

Zamacois, Joaquín. Temas de estética y de historia de la música. Barcelona: Idea Books, 2003. 